\title{
Article \\ Lead Dependent Tricuspid Valve Dysfunction-Risk Factors, Improvement after Transvenous Lead Extraction and Long-Term Prognosis
}

\author{
Anna Polewczyk ${ }^{1,2, *} \mathbb{C}$, Wojciech Jacheć ${ }^{3}\left(\mathbb{D}\right.$, Dorota Nowosielecka ${ }^{4}$, Andrzej Tomaszewski ${ }^{5}$, \\ Wojciech Brzozowski ${ }^{5}$, Dorota Szczęśniak-Stańczyk ${ }^{5}$, Krzysztof Duda ${ }^{6}$ and Andrzej Kutarski ${ }^{6}$ \\ 1 Department of Physiology, Patophysiology and Clinical Immunology, \\ Collegium Medicum of Jan Kochanowski University, 25-369 Kielce, Poland \\ 2 Department of Cardiac Surgery, Świętokrzyskie Centrum of Cardiology, 25-736 Kielce, Poland \\ 3 2nd Department of Cardiology, Zabrze, Faculty of Medical Science in Zabrze, \\ Medical University of Silesia in Katowice, 41-800 Zabrze, Poland; wjachec@interia.pl \\ 4 Department of Cardiology, The Pope John Paul II Province Hospital of Zamość, 22-400 Zamosc, Poland; \\ dornowos@wp.pl \\ 5 Department of Cardiology, Medical University of Lublin, 20-059 Lublin, Poland; \\ benecho2008@gmail.com (A.T.); brzozo@wp.pl (W.B.); dorotasstanczyk@gmail.com (D.S.-S.) \\ 6 Department of Cardiac Surgery, Masovian Specialistic Hospital of Radom, 26-617 Radom, Poland; \\ kadeder@gmail.com (K.D.); a_kutarski@yahoo.com (A.K.) \\ * Correspondence: annapolewczyk@wp.pl; Tel.:+48-600024074
}

\section{check for}

updates

Citation: Polewczyk, A.; Jacheć, W.; Nowosielecka, D.; Tomaszewski, A.; Brzozowski, W.; Szczęśniak-Stańczyk, D.; Duda, K.; Kutarski, A. Lead Dependent Tricuspid Valve Dysfunction-Risk Factors, Improvement after Transvenous Lead Extraction and Long-Term Prognosis. J. Clin. Med. 2022, 11, 89. https:// doi.org/10.3390/jcm11010089

Academic Editor: Patrick De Boever

Received: 18 November 2021

Accepted: 21 December 2021

Published: 24 December 2021

Publisher's Note: MDPI stays neutral with regard to jurisdictional claims in published maps and institutional affiliations.

Copyright: (C) 2021 by the authors. Licensee MDPI, Basel, Switzerland. This article is an open access article distributed under the terms and conditions of the Creative Commons Attribution (CC BY) license (https:// creativecommons.org/licenses/by/ $4.0 /)$.

\begin{abstract}
Background: Lead-related tricuspid valve dysfunction (LDTVD) has not been studied in a large population and its management remains controversial. Methods: An analysis of the clinical data of 2678 patients undergoing transvenous lead extraction (TLE) in years 2008-2021 was conducted, with a separate group of 119 patients with LDTVD. Potential risk factors for LDTVD, improvement in valve function, and long-term prognosis after TLE were assessed. Results: LDTVD was diagnosed in $4.44 \%$ of patients referred for lead extraction due to different reasons. The most common mechanism of LDTVD was propping upward or clamping down the leaflet by the lead (85.71\%). The probability of LDTVD was higher in female sex, patients with valvular heart disease, atrial fibrillation, heart failure, large right ventricle and high pulmonary artery systolic pressure, the presence of only pacing lead, and in case of collision of the lead with tricuspid valve and adhesion of the lead to the heart structures. The prognosis of patients with LDTVD was worse, however, patients with improved valve function after TLE showed a significantly better long-term survival. Conclusions: Lead dependent tricuspid valve dysfunction is a potentially serious condition that requires thorough diagnostics and thoughtful management. The risk factors for LDTVD are primarily related to the course of the lead and its adhesion to the heart structures. Improvement of tricuspid valve function after TLE is observed in $35.29 \%$ of patients Patients with LDTVD have a worse long-term survival, but the improvement in valve function following TLE contributes to a significant reduction in mortality.
\end{abstract}

Keywords: lead dependent tricuspid valve dysfunction; transvenous lead extraction; improvement of tricuspid valve function; prognosis

\section{Introduction}

The problem of tricuspid valve dysfunction after implantation of an endocardial lead was considered from the beginning of pacing era [1,2]. In the following years, there were divergent reports on lead dependent tricuspid valve dysfunction (LDTVD). Most studies confirm the deterioration of tricuspid valve (TV) function in patients with cardiac implantable electronic devices (CIED) [2-11], but some reports contradict the presence of this phenomenon [12-14]. Previous researches were often based on small populations with a short follow-up period and sometimes did not include pre-implantation echocardiography. Currently, there have been several reports assessing the occurrence of LDTVD in a large 
group of patients and a longer follow-up period after CIED implantation [15-17]. All these studies confirm the incidence of LDTVD increasing over time and look for potential risk factors for worsening of tricuspid valve function. The present study is, to our knowledge, based on the largest population to date and includes an analysis of many factors that may influence the development of LDTVD and an assessment of the possibility of improving tricuspid valve function and long term survival after transvenous lead extraction.

\section{Materials and Methods}

\subsection{Patient Population}

A total of 3500 patients who underwent transvenous lead extraction (TLE) procedures by one key operator at three high volume centers between June 2008 and September 2021 were included into this study. All information regarding the patient and the procedure was entered into the computer database on a current basis. Patients without complete echocardiographic findings before and after TLE were excluded. Finally, a total of 2678 patients were enrolled in this study. Patients were divided into two main groups: Group 1 consisted of $119(4.44 \%)$ of patients with lead dependent tricuspid valve dysfunction and Group 2 consisted of 2559 patients without LDTVD. Additionally, an analysis of two LDTVD subgroups was performed-with and without improvement in tricuspid valve function after TLE (Supplementary File).

\subsection{Baseline Parameters}

Demographic data, comorbidities and history of pacing were analyzed. The incidence of coronary heart disease, cardiomyopathy, valvular heart diseases and other comorbidities: hypertension, atrial fibrillation, congestive heart failure, diabetes, renal failure, long-term anticoagulation, and Charlson's comorbidity index, was compared in the studied groups. The comparison of indication-related, system-related and history of pacing related factors in patients with and without LDTVD was also conducted including frequency of occurrence: lead -related infective endocarditis (LRIE), local, pocket infection and non-infective indications for TLE, type of implanted device, number of implanted leads, location of the tip of the lead, abnormal elongated loop of the lead and dwell time of the leads. The complexity of procedures, effectiveness of TLE, presence of complications and short-, medium- and long-term mortality after TLE were also compared in the study groups.

\subsection{Echocardiography}

Transthoracic echocardiography (TTE) was performed in all patients before and after transvenous lead extraction. Transesophageal echocardiography (TEE) was performed before and after TLE in all of patients undergoing TLE in years 2008-2015. A total of 90\% of TLE procedures have been continuously monitored by TEE since 2016 with the precise assessment of TV function before, during and after procedure.

TTE and TEE in our series was performed using Philips iE33 (Phillips Healthcare, Andover, MA, USA) and GE Vivid S 70 GE Healthcare machines (General Electric Company, Boston, MA, USA) equipped with X7-2t Live 3D (Phillips Healthcare, Andover, MA, USA) or 6VT-D probes (General Electric Company, Boston, MA, USA). All recordings were archived and carefully assessed by two experienced cardiologists who were blinded to the clinical data.

Tricuspid regurgitation (TR) severity was graded semi-quantitatively using colored and continuous wave Doppler data using a multi-parametric approach [18,19] including valve morphology, colour flow jet, continuous wave signal of the jet, vena contracta width, and were categorized in three groups: no, trace or mild (0, 1st, 2nd Grades), moderate (3rd Grade), and severe (4th Grade). Lead removal associated improvement of TR was defined by reduction of TR from severe to moderate/mild or from moderate to mild comparing echocardiography studies before and after TLE. Pulmonary artery systolic pressure (PASP) was calculated as the sum of the tricuspid jet gradient (assessed by Doppler) and right atrial pressure. 


\subsection{Definitions}

Lead dependent tricuspid valve dysfunction was defined as significant or severe tricuspid regurgitation (or stenosis) resulting from the documented influence of the lead on the valve leaflets or chordae tendinae. LDTVD was recognized based on the visualization of one of the triggering mechanisms of TR: propping the leaflet by the lead or impingement of the leaflet by the lead or presence of the loop of lead irritating the TV or perforation of the leaflet with the lead.

Lead extraction procedure was defined according to the most recent guidelines on the management of lead-related complications (HRS 2017 and EHRA 2018) [20,21]. Indications for TLE and type of periprocedural complications were defined according to the 2017 HRS Expert Consensus Statement on Cardiovascular Implantable Electronic Device Lead Management and Extraction [20].

\subsection{Transvenous Lead Extraction Procedure}

Most TLE procedures were performed using nonpowered mechanical systems such as Byrd polypropylene dilator sheaths (Cook Medical, Leechburg, PA, USA) if only possible via the implant vein. If technical difficulties arose, alternative venous approaches or additional tools such as Evolution (Cook Medical, Leechburg, PA, USA), TightRail (Spectranetix, Sunnyvale, CA, USA), lassos (Multi-Snare ${ }^{\circledR}$ Device PFM Medical, Inc. Carlsbad, CA, USA), basket catheters (Cook Medical Inc., Bloomington, IN, USA) were utilized. The excimer laser was not applied.

\subsection{Indications for Transvenous Lead Extraction in Whole Examined Population of Patients}

Main indications for TLE were: 1. infectious complications: local pocket infection, bacteraemia with or without endocarditis, or any combination of these presentations together 2 non-infectious indications including: mechanical lead damage (electric failure), lead dysfunction (exit/entry block, dislodgement, extracardiac pacing, perforation), upgrading, downgrading and another reasons of prevention of lead abandonment-prophylactic indications e.g. atrial fibrillation, overmuch of leads, threatener/potentially threatener lead (free ending, left heart, LDTVD and other (MRI indication, cancer, pain of pocket, loss of indication for pacing/ICD) and recapture venous access (symptomatic occlusion, superior vena cava syndrome, lead replacement/upgrading).

\subsection{Statistical Analysis}

The Shapiro-Wilk test showed that most continuous variables were normally distributed. For uniformity, all continuous variables are presented as the mean \pm standard deviation and were compared using " $U$ " Mann-Whitney test. Categorical data are presented as absolute numbers and percentages and were compared using Chi-square test with Yates correction.

Logistic linear regression was applied to identify the variables associated with LDTVD. To the univariable regression analysis were included demographic, clinical, echocardiographic, and CIED related (outside derivate) data which reached the $p$ value $<0.1$ in the "U" Mann-Whitney or $\mathrm{Chi}^{2}$ tests. To the multivariable regression analysis data reached $p<0.1$ under univariable analysis were included.

The results of the regression analysis were reported as odds ratio with corresponding $95 \%$ confidence intervals (CIs).

Survival analysis based on Kaplan-Meier curves and log-rank tests were used to assess the event-free survival between groups of patients separated on the basis of LDTVD presence (divided in to two groups regarding on the TLE impact on the LDTVD).

The results were considered statistically significant if $p<0.05$. Statistical analysis was performed with Statistica version 13.3 (TIBCO Software Inc., Palo Alto, CA, USA).

\subsection{Approval of the Bioethics Committee}

All patients gave their informed written consent to undergo TLE and use anonymous data from their medical records, approved by the Bioethics Committee at the Regional 
Chamber of Physicians in Lublin No. 288/2018/KB/VII. The study was carried out in accordance with the ethical standards of the 1964 Declaration of Helsinki.

\section{Results}

\subsection{Baseline Characteristics}

Among 2678 patients referred to TLE, 119 (4.44\%) were diagnosed with LDTVD. Patients with LDTVD were referred for lead extraction for various reasons and only $37.82 \%$ of LDTVD was the primary indication of TLE. In as far as $62.18 \%$ LDTVD is diagnosed occasionally as important but co-existing indication. A common mechanism of LDTVD was propping upward or clamping (drawing) down the leaflet by the lead (85.71\%); another mechanism as impingement of the leaflet by the lead presence (irritation and degeneration), perforation of the leaflet with the lead or connection of leaf with the lead with scar were rare (11.76\%). In direct echocardiographic evaluation (TEE after procedure), improvement in TV function, defined as perceptible, was found in $27.73 \%$ of patients, in $10.92 \%$ it showed a significant improvement, while in $61.34 \%$ of patients it was not significant. The reduction of TR after TLE was observed in $35.29 \%$ of patients: a one-degree reduction in TR was diagnosed in $31.93 \%$ of patients, and a 2-degree reduction in $3.36 \%$ of patients.

A total of 40 patients out of 119 (33.60\%) achieved the criterion of TV plastic, but only $18(15.13 \%)$ were referred for surgery, the rest are under observation (Table 1$)$.

Table 1. Basic information about 119 patients with confirmed LDTVD.

\begin{tabular}{|c|c|c|c|c|c|}
\hline \multicolumn{3}{|c|}{ Prelininary and verifired diagnosis of LDTVD } & \multicolumn{3}{|c|}{$\begin{array}{c}\text { Effect of TLE on severity of TR in pts with LDTVD impression } \\
\text { of echocardioigraphist }\end{array}$} \\
\hline Preliminary diagnosis of LDTVD & 125 & $4.90 \%$ & Insignificant & 73 & $61.34 \%$ \\
\hline Confirmed diagnosis of LDTVD & 119 & $4.44 \%$ & Perceptible & 33 & $27.73 \%$ \\
\hline All patients & 2678 & $100.00 \%$ & Significant & 13 & $10.92 \%$ \\
\hline \multicolumn{3}{|c|}{$\begin{array}{l}\text { Main/predominant Indications for lead extraction in patient } \\
\text { with LDTVD }\end{array}$} & All LDTVD patients & 119 & $100.00 \%$ \\
\hline $\begin{array}{l}\text { Symptomatic lead dependent } \\
\text { TV dysfunction }\end{array}$ & 45 & $37.82 \%$ & & & \\
\hline $\begin{array}{l}\text { Lead damage/dysfunction } \\
\quad \text { (lead replacement) }\end{array}$ & 39 & $32.78 \%$ & \multicolumn{3}{|c|}{ Changes of degree of TR after TLE (degrees) } \\
\hline $\begin{array}{l}\text { Systemic infection or local or } \\
\text { mixed infection }\end{array}$ & 21 & $17.65 \%$ & No change (the same) & 77 & $64.71 \%$ \\
\hline $\begin{array}{l}\text { Upgrading, downgrading, prevention of } \\
\text { lead abandonment }\end{array}$ & 11 & $9.24 \%$ & Reduction of TR for 1 degree & 38 & $31.93 \%$ \\
\hline $\begin{array}{l}\text { Recapture venous access (symptomatic } \\
\text { occlusion, lead replacement/upgrading) }\end{array}$ & 3 & $2.52 \%$ & Reduction of TR for 2 degrees & 4 & $3.36 \%$ \\
\hline All LDTVD patients & 119 & $100.00 \%$ & All LDTVD patients & 119 & $100.00 \%$ \\
\hline \multicolumn{3}{|c|}{$\begin{array}{c}\text { Mechanism of TV dysfunction (partial immobilisation of the leaf or } \\
\text { irritation causing degeneration) }\end{array}$} & $\begin{array}{l}\text { Average right ventricular lead } \\
\text { dwell time }\end{array}$ & 104.57 & SD 69.8 \\
\hline Propping upward the leaflet by the lead & 45 & $37.82 \%$ & \multicolumn{3}{|c|}{ LDTVD and cardiac surgery after TLE } \\
\hline $\begin{array}{l}\text { Drawing down } \mathrm{f} \text { the leaflet by the } \\
\text { lead (immobilisation) }\end{array}$ & 57 & $47.90 \%$ & Indication reached-observation & 22 & $18.49 \%$ \\
\hline $\begin{array}{l}\text { Impingement of the leaflet by the lead } \\
\text { presence (irritation) }\end{array}$ & 3 & $2.52 \%$ & No indication-observation only & 74 & $62.19 \%$ \\
\hline Perforation of the leaflet with the lead & 3 & $2.52 \%$ & Referred for TV plastic & 18 & $15.13 \%$ \\
\hline Connection of lead with the lead with scar & 11 & $9.24 \%$ & $\begin{array}{l}\text { Not considered (contraindication, } \\
\text { lack of agreement) }\end{array}$ & 5 & $4.20 \%$ \\
\hline All LDTVD patients & 119 & $100.00 \%$ & ALL patients with LDTVD & 119 & $100.00 \%$ \\
\hline
\end{tabular}


Patients with LDTVD tended to be older at the time of TLE ( $p=0.087)$ and more often of the female sex. LDTVD group was characterized by significantly higher incidence of valvular heart disease, presence of valvular implant and severe heart failure (NYHA Class III and IV). Patients with LDTVD were more likely to have permanent atrial fibrillation $(\mathrm{AF})$, renal failure and used long-term anticoagulation (Table 2).

Table 2. Clinical data-classification according to the occurrence of LDTVD.

\begin{tabular}{|c|c|c|c|c|c|}
\hline $\begin{array}{c}\text { Patient-Related Potential Risk } \\
\text { Factors of LDTVD }\end{array}$ & \multicolumn{2}{|c|}{ LDTVD (All Patients with LDTVD) } & \multicolumn{3}{|c|}{ NO LDTVD (Control Group) } \\
\hline Number of patients/number of the group & 119 & 1 & 2559 & 2 & $p$ \\
\hline Presented values & Count/average & $\% / S d$ & Count/average & $\% / \mathrm{Sd}$ & 1 vs. 2 \\
\hline Patient's age during TLE & 68.09 & 15.05 & 66.90 & 14.52 & 0.087 \\
\hline $\begin{array}{l}\text { Patient's age during first } \\
\text { system implantation }\end{array}$ & 58.43 & 18.96 & 58.32 & 16.18 & 0.485 \\
\hline Sex (\% of female patients) & 67 & $56.30 \%$ & 995 & $38.88 \%$ & 0.001 \\
\hline Baseline heart diseases: IHD, MI & 69 & $57.98 \%$ & 1494 & $58.38 \%$ & 0.995 \\
\hline $\begin{array}{l}\text { Baseline heart diseases: } \\
\text { primary cardiomyopathy }\end{array}$ & 13 & $10.92 \%$ & 343 & $13.40 \%$ & 0.562 \\
\hline $\begin{array}{l}\text { Baseline heart diseases: valvular } \\
\text { heart disease }\end{array}$ & 10 & $8.40 \%$ & 59 & $2.31 \%$ & 0.001 \\
\hline $\begin{array}{c}\text { Baseline heart diseases: } \\
\text { post-inflammatory, congenital, } \\
\text { channelopathies, } \\
\text { neurocardiogenic, unknown }\end{array}$ & 27 & $22.69 \%$ & 662 & $25.87 \%$ & 0.566 \\
\hline NYHA class I-IV & 2.20 & 0.80 & 1.84 & 0.67 & $<0.001$ \\
\hline AF permanent & 50 & $42.02 \%$ & 565 & $22.08 \%$ & 0.001 \\
\hline Hypertension & 66 & $55.46 \%$ & 1487 & $58.11 \%$ & 0.777 \\
\hline Diabetes (any) & 21 & $17.65 \%$ & 534 & $20.87 \%$ & 0.515 \\
\hline Renal failure (any) & 34 & $28.57 \%$ & 538 & $21.02 \%$ & 0.052 \\
\hline Valvular implant presence & 83 & $18.49 \%$ & 156 & $6.10 \%$ & 0.001 \\
\hline Mechanical valve presence & 15 & $12.61 \%$ & 15 & $3.59 \%$ & 0.001 \\
\hline Previous sternotomy & 24 & $20.17 \%$ & 359 & $14.03 \%$ & 0.07 \\
\hline Long-term anticoagulation & 73 & $61.35 \%$ & 1000 & $39.08 \%$ & 0.001 \\
\hline Charlson's index (points) & 4.99 & 3.56 & 4.83 & 3.69 & 0.352 \\
\hline
\end{tabular}

Abbreviations: AF—atrial fibrillation, IHD—ischaemic heart disease, MI—myocardial infarction, LDTVD—lead dependent tricuspid valve dysfunction, NYHA class-New York Hear Association class, TLE-transvenous lead extraction. Valvular implant: mechanical valve, biological valve, mitral o tricuspid ring.

Improvement in tricuspid valve function after TLE was observed in 42 patients with LDTVD, the remaining 77 did not show changes. The reduction in TR after TLE was found more frequently in older patient (in advanced age during implantation and during TLE) and in patients with ischemic heart disease (Table S1-Supplementary File).

\subsection{Pacing System and TLE-Related Factors}

Indications for TLE in the entire study group included infectious complications in $31.52 \%$ of patients, non-infectious therapeutic indications in $65.10 \%$ and prophylactic indications in $3.40 \%$ of patients.

Patients with LDTVD were referred to TLE more frequently due to non-infectious therapeutic indications, less often due to infectious complications. 
In terms of kind of implanted system, patients with LDTVD more often had pacemakers (AAI, VVI, DDD, CRT-P mode), less often ICD. Excessive loops of the leads passing through the TV were found more frequently in LDTVD group $(20.17 \%$ vs. $4.53 \% ; p=0.001)$, similarly other forms of collision of the lead with TV visible in fluoroscopy $(21.01 \% \mathrm{vs}$. $0.59 \% ; p=0.001)$.

The number of leads and number of abandoned leads was comparable in the studied groups.

Mean lead dwell time in the patient before TLE in the whole study group was $95.36 \pm 67.10$ months and was longer in patients with LDTVD (107.73 \pm 68.90 vs. $95.83 \pm 66.98$ months; $p=0.058)$.

In patients with LDTVD, there was a tendency to more frequent non-apical location of the lead tip ( $p=0.092)$ (Table 3).

Table 3. Indication, system and history of pacing -related factors. Classification according to the occurrence of LDTVD.

\begin{tabular}{|c|c|c|c|c|c|}
\hline & \multicolumn{2}{|c|}{ LDTVD (All Patients with LDTVD) } & \multicolumn{2}{|c|}{ NO LDTVD (Control Group) } & \multirow[b]{2}{*}{$p$} \\
\hline Number of Patients Number of the Group & 119 & 1 & 2559 & 2 & \\
\hline Presented Values & Count/Average & $\% / \mathrm{Sd}$ & Count/Average & $\% / \mathrm{Sd}$ & 1 vs. 2 \\
\hline \multicolumn{6}{|c|}{ TLE Indications } \\
\hline LRIE certain with or without pocket infection & 13 & $10.92 \%$ & 458 & $17.90 \%$ & 0.078 \\
\hline $\begin{array}{l}\text { LRIE probable with or without } \\
\text { pocket infection }\end{array}$ & 4 & $3.36 \%$ & 159 & $6.21 \%$ & 0.279 \\
\hline Local/isolated pocket infection & 4 & $3.36 \%$ & 206 & $8.05 \%$ & 0.099 \\
\hline All infections & 21 & $17.65 \%$ & 823 & $32.16 \%$ & 0.002 \\
\hline Non-infectious prophylactic indications & 5 & $4.20 \%$ & 86 & $3.36 \%$ & 0.788 \\
\hline Non-infectious therapeutic indications & 93 & $78.15 \%$ & 1650 & $64.48 \%$ & 0.002 \\
\hline All non-infectious indications & 98 & $82.35 \%$ & 1736 & $67.84 \%$ & 0.001 \\
\hline \multicolumn{6}{|c|}{ System and history of pacing } \\
\hline Device type-PM (AAI, VVI, DDD, CRT-P) & 100 & $84.03 \%$ & 1786 & $69.79 \%$ & 0.001 \\
\hline Device type-ICD (VVI, DDD) & 9 & $7.56 \%$ & 577 & $22.55 \%$ & 0.001 \\
\hline Device type-CRT-D & 10 & $8.40 \%$ & 196 & $7.66 \%$ & 0.865 \\
\hline Number of leads in the system before TLE & 1.84 & 0.70 & 1.82 & 0.62 & 0.971 \\
\hline Presence of abandoned lead before TLE & 16 & $13.45 \%$ & 270 & $10.55 \%$ & 0.363 \\
\hline Number of abandoned leads before TLE & 0.21 & 0.60 & 0.14 & 0.43 & 0.636 \\
\hline Number of leads in the heart before TLE & 2.03 & 0.82 & 1.95 & 0.73 & 0.459 \\
\hline 4 and $>4$ leads before TLE & 7 & $5.88 \%$ & 73 & $2.85 \%$ & 0.096 \\
\hline One ICD lead before TLE & 18 & $15.13 \%$ & 762 & $29.78 \%$ & 0.001 \\
\hline 2 or more ICD leads before TLE & 2 & $1.68 \%$ & 18 & $7.03 \%$ & 0.493 \\
\hline Apical RV lead location (lead analysis) & 101 & $41.91 \%$ & 2058 & $41.39 \%$ & 0.166 \\
\hline $\begin{array}{l}\text { Out of apical (septal, outfow tract, anterior } \\
\text { wall) RV lead location (lead analysis) }\end{array}$ & 30 & $12.45 \%$ & 483 & $9.71 \%$ & 0.092 \\
\hline Previous TLE in history & 8 & $6.72 \%$ & 135 & $5.28 \%$ & 0.603 \\
\hline $\begin{array}{l}\text { Upgrading or downgrading with } \\
\text { lead abandonment }\end{array}$ & 11 & $9.24 \%$ & 158 & $6.17 \%$ & 0.229 \\
\hline $\begin{array}{l}\text { Excessive long lead loop in the } \\
\text { atrium (fluoroscopy) }\end{array}$ & 18 & $15.13 \%$ & 311 & $12.15 \%$ & 0.374 \\
\hline
\end{tabular}


Table 3. Cont.

\begin{tabular}{|c|c|c|c|c|c|}
\hline \multirow[b]{2}{*}{$\begin{array}{c}\text { Excessive lead loop crossing TV or in the } \\
\text { ventricle (fluoroscopy)-A }\end{array}$} & \multicolumn{2}{|c|}{ LDTVD (All Patients with LDTVD) } & \multicolumn{3}{|c|}{ NO LDTVD (Control Group) } \\
\hline & 24 & $20.17 \%$ & 116 & $4.53 \%$ & 0.001 \\
\hline $\begin{array}{l}\text { Fluoroscopic impression of lead collision } \\
\text { with TV (without loop) to tense or to long-B }\end{array}$ & 25 & $21.01 \%$ & 15 & $0.59 \%$ & 0.001 \\
\hline $\begin{array}{l}\text { Fluoroscopic impression of lead loop } \\
\text { collision with TV-C }\end{array}$ & 25 & $21.01 \%$ & 115 & $4.49 \%$ & 0.001 \\
\hline All lead's collision with TV $(\mathrm{A}+\mathrm{B}+\mathrm{C})$ & 74 & $62.19 \%$ & 246 & $9.61 \%$ & 0.001 \\
\hline $\begin{array}{c}\text { Dwell time of oldest one lead in the patient } \\
\text { before TLE }\end{array}$ & 116.82 & 81.90 & 103.73 & 75.64 & 0.106 \\
\hline $\begin{array}{c}\text { Mean lead dwell time (in the patient) before } \\
\text { TLE (in months) }\end{array}$ & 107.73 & 68.90 & 95.83 & 66.98 & 0.058 \\
\hline
\end{tabular}

Abbreviations: CRT—cardiac resynchronization therapy, ICD—implantable cardioverter defibrillator, LRIE—lead related infective endocarditis, MI-myocardial infarction, LDTVD-lead dependent tricuspid valve dysfunction, PM-pacemaker, RV—right ventricle, TLE—transvenous lead extraction, TV—tricuspid valve.

Improvement of TV function after TLE was visible only in the group of non-infectious prophylactic indications. There was no association between implanted system-related factors and appearance of improvement in TV function after TLE (Table S2 - Supplementary File).

Complex (second line) tools such as Evolution, TightRail or lasso catheter were more often required when performing TLE procedures in patients with LDTVD—this was due to more frequent technical problems in this group of patients (10.08\% vs. $4.42 \% ; p=0.07)$. In the LDTVD group, tip or lead fragment retention was more frequent-partial radiological success was observed in $8.40 \%$ of patients compared to $3.63 \%$ in patients without LDTVD $(p=0.014)$. The effectiveness of TLE and the percentage of major and minor complications did not differ significantly in the studied groups. Long-term mortality after TLE was comparable in the LDTVD group and without lead-dependent tricuspid valve dysfunction (Table 4).

Table 4. TLE procedure complexity, efficacy, complications, outcomes and long-term mortality after TLE. Classification according to the occurrence of LDTVD.

TLE Procedure Complicity, Efficacy, Complications, Outcomes and Long-Term Mortality after TLE

\begin{tabular}{|c|c|c|c|c|c|}
\hline Number of Patients Number of the Group & 119 & 1 & 2559 & 2 & $p$ \\
\hline Presented Values & Count/Average & $\% / S d$ & Count/Average & $\% / \mathrm{Sd}$ & 1 vs. 2 \\
\hline \multicolumn{6}{|c|}{ TLE procedure complexity } \\
\hline Procedure duration (sheath to sheath) & 29.66 & 35.90 & 14.44 & 21.60 & 0.242 \\
\hline $\begin{array}{l}\text { Average time of single lead extraction } \\
\text { (sheath-to sheath/number of extracted leads) }\end{array}$ & 11.05 & 17.24 & 8.64 & 12.03 & 0.512 \\
\hline Technical problem during TLE (any) & 29 & $24.37 \%$ & 531 & $20.75 \%$ & 0.356 \\
\hline Number of big technical problems & 1.71 & 1.15 & 1.34 & 0.65 & 0.153 \\
\hline One technical problem only & 16 & $13.45 \%$ & 322 & $12.58 \%$ & 0.842 \\
\hline Two or more technical Problems & 12 & $10.08 \%$ & 113 & $4.42 \%$ & 0.007 \\
\hline \multicolumn{6}{|c|}{ Utility of additional tools } \\
\hline Evolution (old and new) or TighRail & 6 & $5.04 \%$ & 38 & $1.49 \%$ & 0.008 \\
\hline Lasso catheter/snare & 9 & $7.56 \%$ & 94 & $3.67 \%$ & 0.050 \\
\hline Basket catheter & 1 & $0.84 \%$ & 19 & $0.74 \%$ & 0.683 \\
\hline
\end{tabular}


Table 4. Cont.

TLE Procedure Complicity, Efficacy,

Complications, Outcomes and Long-Term Mortality after TLE

\section{LDTVD (All Patients with LDTVD) NO LDTVD (Control Group)}

\begin{tabular}{|c|c|c|c|c|c|}
\hline \multicolumn{6}{|c|}{ TLE efficacy and complications } \\
\hline Major complications (any) & 1 & $0.84 \%$ & 50 & $1.95 \%$ & 0.613 \\
\hline Hemopericardium & 1 & $0.84 \%$ & 28 & $1.09 \%$ & 0.834 \\
\hline Haemothorax & 0 & $0.00 \%$ & 3 & $0.31 \%$ & 0.298 \\
\hline $\begin{array}{l}\text { Tricuspid valve damage (significant) } \\
\text { during TLE }\end{array}$ & 0 & $0.00 \%$ & 17 & $0.66 \%$ & 0.771 \\
\hline Rescue cardiac surgery & 0 & $0.00 \%$ & 23 & $0.90 \%$ & 0.604 \\
\hline Minor complications (any) & 14 & $11.76 \%$ & 204 & $7.98 \%$ & 0.172 \\
\hline $\begin{array}{l}\text { Death procedure related (intra, } \\
\text { post-procedural) }\end{array}$ & 0 & $0.00 \%$ & 0 & $0.00 \%$ & $\mathrm{~N}$ \\
\hline $\begin{array}{l}\text { Death indication-related (intra, } \\
\text { post-procedural) }\end{array}$ & 0 & $0.00 \%$ & 1 & $0.04 \%$ & 0.026 \\
\hline $\begin{array}{l}\text { Partial radiological success (remained tip or } \\
\qquad<4 \mathrm{~cm} \text { lead fragment) }\end{array}$ & 10 & $8.40 \%$ & 93 & $3.63 \%$ & 0.014 \\
\hline Full clinical success & 118 & $99.16 \%$ & 2504 & $97.85 \%$ & 0.17 \\
\hline Full procedural success & 108 & $90.76 \%$ & 2446 & $95.58 \%$ & 0.191 \\
\hline \multicolumn{6}{|c|}{ Long-term mortality after TLE } \\
\hline $\begin{array}{l}\text { Alive during } 1658 \pm 1203(1-5519) \text { days of } \\
\text { follow up }\end{array}$ & 78 & $65.55 \%$ & 1796 & $70.18 \%$ & 0.329 \\
\hline $\begin{array}{l}\text { Death during all } 1658 \pm 1203 \text { (1-5519) days } \\
\text { of follow up }\end{array}$ & 41 & $34.45 \%$ & 763 & $29.82 \%$ & 0.329 \\
\hline
\end{tabular}

Abbreviations: LDTV—lead dependent tricuspid valve dysfunction, TLE—transvenous lead extraction.

There was no direct relationship between the efficacy of TLE and the improvement in tricuspid valve function after procedure. Patients with improved tricuspid valve function after TLE showed a better long-term survival (Table S3-Supplementary File).

\subsection{Echocardiographic Findings}

Patients with LDTVD more often demonstrated mitral valve insufficiency, greater dimension of the right ventricle (RV) and higher pulmonary systolic pressure (PASP). Left ventricular ejection fraction (LVEF) no differ significantly between compared groups. Significant and severe (Grade 3 and 4 ) tricuspid regurgitation was more frequently observed in patients with LDTVD (40.34\%vs $14.10 \% ; p=0.001$ and $47.90 \%$ vs. $2.74 ; p=0.001)$.

In the LDTVD group more frequent occurred adhesion of the lead to the walls of the heart, especially to the tricuspid apparatus $(14.29 \%$ vs. $4.85 \% ; p=0.001)$ and more often were observed excessively elongated loops of the leads (similarly to fluoroscopy results) $(36.13 \%$ vs. $17.60 \% ; p=0.001)$ (Table 5, Figure 1$)$.

There was a trend towards improvement of TV function after TLE in patients with a smaller right ventricular size $(p=0.081)$. The remaining echocardiographic findings did not correlate with a reduction in TV regurgitation after TLE (Table S4-Supplementary File).

\subsection{Univariate and Multivariate Logistic Regression of Risk Factors for LDTVD}

Univariate analysis showed, that factors predisposing to LDTVD were: female gender, valvular heart disease, presence of valvular implant, higher NYHA class, permanent $\mathrm{AF}$, long-term anticoagulation, larger diameter of RV, higher PASP, and strong connective tissue scar connection of the lead with heart structures (TV, RA or RV). There was also a tendency 
to influence the mean lead dwell time $(p=0.062)$. The presence of only the pacing lead (no HV lead) also increased the probability of LDTVD.

Table 5. Echocardiographic findings/abnormalities. Classification according to the occurrence of LDTVD.

\begin{tabular}{|c|c|c|c|c|c|}
\hline $\begin{array}{l}\text { Echocardiographic } \\
\text { Findings/Abnormalities Recorded in } \\
\text { Patients with or without LDTVD }\end{array}$ & \multicolumn{2}{|c|}{ LDTVD (All Patients with LDTVD) } & \multicolumn{3}{|c|}{ NO LDTVD (Control Group) } \\
\hline Number of Patients Number of the Group & 119 & 1 & 2559 & 2 & $p$ \\
\hline Presented Values & Count/Average & $\% / \mathrm{Sd}$ & Count/Average & $\% / \mathrm{Sd}$ & 1 vs. 2 \\
\hline \multicolumn{6}{|c|}{ Echocardiography before and after TLE } \\
\hline Average LVEF & 48.58 & 13.27 & 49.53 & 15.46 & 0.153 \\
\hline Mitral regurgitation (significant) & $24 / 112$ & $21.43 \%$ & $352 / 2528$ & $13.92 \%$ & 0.037 \\
\hline PASP (mmHg) & 40.73 & 13.41 & 30.49 & 13.16 & 0.001 \\
\hline RV diameter (mm) & 35.51 & 7.65 & 31.24 & 6.00 & 0.001 \\
\hline \multicolumn{6}{|c|}{ Tricuspid Regurgitation before TLE } \\
\hline Non-significant $(0,1,2$ grade $)$ & $14 / 119$ & $11.77 \%$ & $2123 / 2553$ & $83.16 \%$ & 0.001 \\
\hline Significant (3 grade) & $48 / 119$ & $40.34 \%$ & $360 / 2553$ & $14.10 \%$ & 0.001 \\
\hline Severe (4 grade) & $57 / 119$ & $47.90 \%$ & $70 / 2553$ & $2.74 \%$ & 0.001 \\
\hline \multicolumn{6}{|c|}{ Any shadows on the leads before TLE } \\
\hline Any shadows on leads before TLE & $53 / 119$ & $52.94 \%$ & $1264 / 2554$ & $49.39 \%$ & 0.336 \\
\hline Connecting tissue surrounding the lead & $7 / 119$ & $5.88 \%$ & $262 / 2557$ & $10.25 \%$ & 0.164 \\
\hline Blood cloth on the lead & $11 / 119$ & $9.24 \%$ & $164 / 2557$ & $6.41 \%$ & 0.336 \\
\hline Vegetation-like mass & $1 / 119$ & $0.84 \%$ & $107 / 2557$ & $4.18 \%$ & 0.116 \\
\hline Thicker lead & 26/119 & $21.85 \%$ & $470 / 2557$ & $18.38 \%$ & 0.406 \\
\hline Vegetation & $16 / 119$ & $13.45 \%$ & $450 / 2556$ & $17.61 \%$ & 0.296 \\
\hline $\begin{array}{l}\text { Strong connective tissue scar connection of } \\
\text { the lead with heart structures (any) }\end{array}$ & $28 / 115$ & $24.35 \%$ & $315 / 2498$ & $12.61 \%$ & 0.001 \\
\hline $\begin{array}{l}\text { Strong connective tissue scar connection of } \\
\text { the lead with tricuspid apparatus }\end{array}$ & $17 / 119$ & $14.29 \%$ & $124 / 2557$ & $4.85 \%$ & 0.001 \\
\hline $\begin{array}{l}\text { Strong connective tissue scar connection of } \\
\text { the lead with RA wall }\end{array}$ & $11 / 119$ & $9.24 \%$ & $99 / 2557$ & $3.87 \%$ & 0.008 \\
\hline $\begin{array}{c}\text { Strong connective tissue scar connection of } \\
\text { the lead with SVC }\end{array}$ & $5 / 119$ & $4.20 \%$ & $104 / 2557$ & $4.07 \%$ & 0.869 \\
\hline $\begin{array}{l}\text { Strong connective tissue scar connection of } \\
\text { the lead with RV wall }\end{array}$ & $14 / 119$ & $11.77 \%$ & $157 / 2557$ & $6.14 \%$ & 0.073 \\
\hline \multicolumn{6}{|c|}{ Loops of the leads } \\
\hline $\begin{array}{l}\text { Excessive loops of the leads in the heart } \\
\text { (any)/ECHO }\end{array}$ & $43 / 119$ & $36.13 \%$ & $450 / 2558$ & $17.59 \%$ & 0.001 \\
\hline Excessive loop in the RA & $27 / 119$ & $22.69 \%$ & $331 / 2558$ & $12.94 \%$ & 0.001 \\
\hline Excessive loop in the TV & $27 / 119$ & $22.69 \%$ & $94 / 2558$ & $2.68 \%$ & 0.001 \\
\hline Excessive loop in the RV & $20 / 119$ & $16.81 \%$ & $124 / 2558$ & $4.85 \%$ & 0.001 \\
\hline
\end{tabular}

Abbreviations: LVEF-left ventricular ejection fraction, LDTVD—lead dependent tricuspid valve dysfunction, PASP - pulmonary artery systolic pressure, RA — right atrium, RV—right ventricle, SVC—superior vena cava, TLE-transvenous lead extraction, TV—-tricuspid valve. 


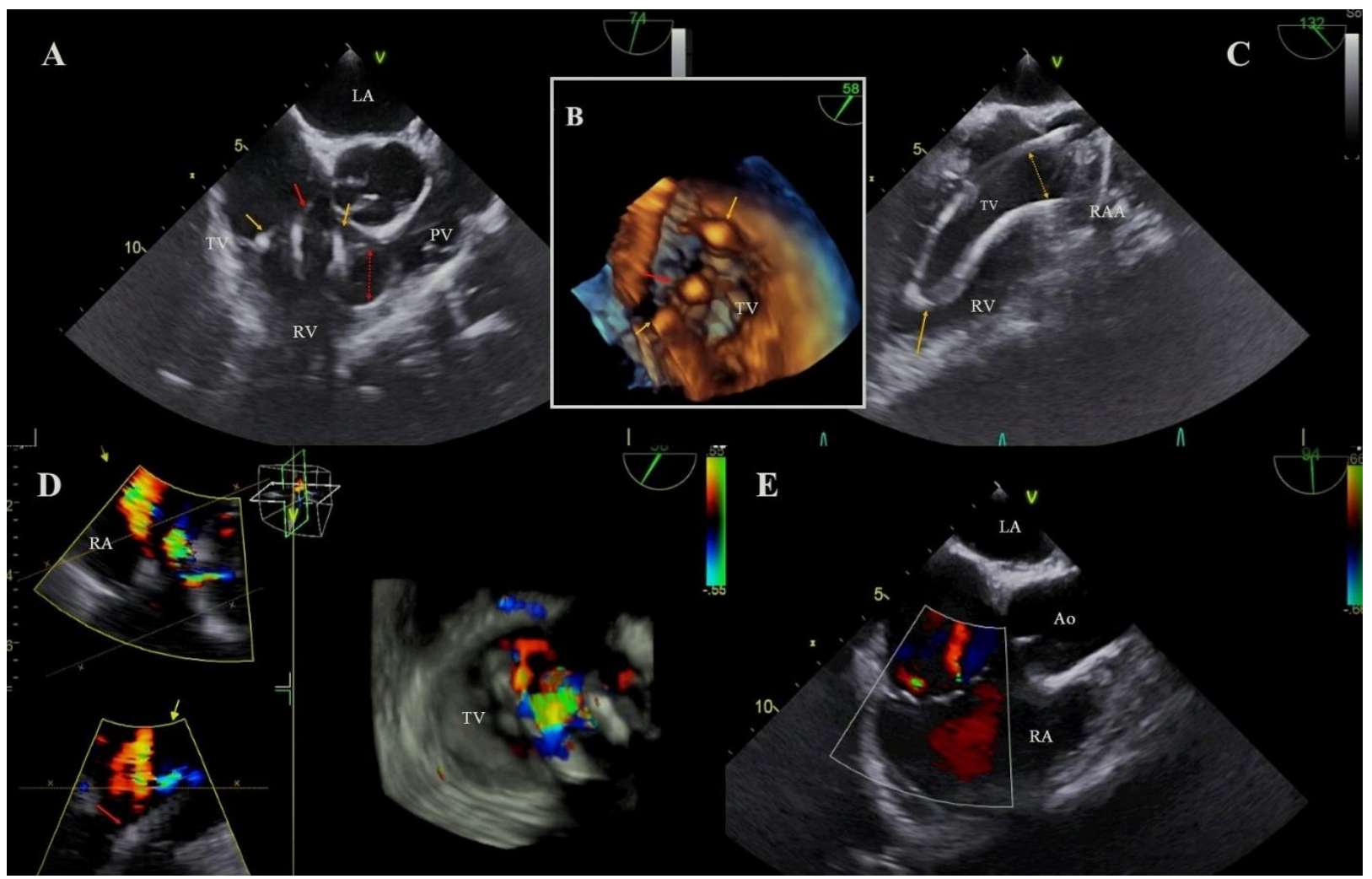

Figure 1. The excessive loop of the lead as a reason of LDTVD. (A): The loop of the atrial lead in the tricuspid valve (TV), entering the right ventricular (RV) lumen (yellow arrows). A ventricular lead through the TV forms a loop in the right ventricular outflow tract RVOT (red arrows). TEE 2D. (B): Three leads visible in the tricuspid valve, atrial loop of the lead distributed in the commissures (yellow arrows), centrally located ventricular lead (red arrow). TEE 3D. (C): After removal of the ventricular lead (TLE), the atrial lead loop was clearly visible. TEE 2D. (D): Two jets of a significant tricuspid regurgitation (TR) to the right atrium resulting from the collision of the three leads with the valve leaflets. TEE 3D color doppler. (E): The effect after TLE procedure. Two jets of non-significant tricuspid regurgitation remained. TEE 2D.

The multivariate analysis confirmed the increased probability of LDTVD in female sex, patients with valvular heart disease, atrial fibrillation, heart failure with high NYHA class, larger RV and higher PASP and in case of collision of the lead with TV and strong connective tissue scar connection of the lead with heart structures especially with RA wall. The presence of only the pacing lead (no HV lead) also increased the probability of LDTVD (Table 6).

Table 6. Factors connected with LDTVD presence. Results of uni- and multi-variable logistic regression analysis.

\begin{tabular}{|c|c|c|c|c|c|c|}
\hline \multirow[t]{2}{*}{19 LDTVD vs. Other (2559) } & \multicolumn{3}{|c|}{ Univariate Analysis } & \multicolumn{3}{|c|}{ Multivariate Analysis } \\
\hline & OR & $95 \%$ CI & $p$ & OR & $95 \% \mathrm{CI}$ & $p$ \\
\hline Patient's age during TLE (by year) & 1.008 & $0.995-0.021$ & 0.239 & & & \\
\hline Female gender & 1.927 & $1.327-1.797$ & $<0.001$ & 2.441 & $1.514-3.937$ & $<0.001$ \\
\hline $\begin{array}{c}\text { Baseline heart diseases: valvular } \\
\text { heart disease }\end{array}$ & 3.248 & $1.860-1.669$ & $<0.001$ & 2.755 & $1.153-6.580$ & 0.022 \\
\hline
\end{tabular}


Table 6. Cont.

\begin{tabular}{|c|c|c|c|c|c|c|}
\hline \multirow[t]{2}{*}{19 LDTVD vs. Other (2559) } & \multicolumn{3}{|c|}{ Univariate Analysis } & \multicolumn{3}{|c|}{ Multivariate Analysis } \\
\hline & OR & $95 \% \mathrm{CI}$ & $p$ & OR & $95 \%$ CI & $p$ \\
\hline NYHA class (by 1) & 2.092 & $1.609-2.720$ & $<0.001$ & 2.060 & $1.443-2.940$ & $<0.001$ \\
\hline PASP (by $1 \mathrm{~mm} \mathrm{Hg}$ ) & 1.047 & $1.035-1.060$ & $<0.001$ & 1.030 & $1.014-1.046$ & $<0.001$ \\
\hline RV diameter (by $1 \mathrm{~mm}$ ) & 1.099 & $1.073-1.126$ & $<0.001$ & 1.079 & $1.043-1.116$ & $<0.001$ \\
\hline Permanent AF & 2.555 & $1.750-3.730$ & $<0.001$ & 1.776 & $0.985-3.201$ & 0.056 \\
\hline Mitral valve insufficiency & 1.897 & $1.214-2.963$ & 0.004 & 1.038 & $0.586-1.840$ & 0.879 \\
\hline Renal failure (any) & 1.447 & $0.956-2.191$ & 0.081 & 1.058 & $0.631-1.773$ & 0.831 \\
\hline Valvular implant presence & 2.801 & $1.633-4.804$ & $<0.001$ & 1.045 & $0.431-2.534$ & 0.922 \\
\hline Previous sternotomy & 1.377 & $0.855-2.216$ & 0.187 & & & \\
\hline Long term anticoagulation & 2.254 & $1.547-3.284$ & $<0.000$ & 1.152 & $0.634-2.092$ & 0.643 \\
\hline $\begin{array}{l}\text { Presence of pacing leads only (AAI } \\
\text { VVI VDD DDD CRTP) }\end{array}$ & 2.116 & $1.321-3.390$ & 0.002 & 1.812 & $1.001-3.279$ & 0.050 \\
\hline $\begin{array}{l}\text { Presence of HV lead(s) } \\
\text { (without CRTD) }\end{array}$ & 0.406 & $0.238-0.693$ & $<0.001$ & & & \\
\hline$\geq 4$ leads before TLE & 1.848 & $0.788-4.334$ & 0.158 & & & \\
\hline $\begin{array}{l}\text { Mean lead dwell time before TLE } \\
\text { (by year) }\end{array}$ & 1.030 & $0.999-1.063$ & 0.062 & 0.969 & $0.925-1.015$ & 0.184 \\
\hline $\begin{array}{l}\text { * Lead(s) collision with TV (including } \\
\text { excessive loop (s) of lead (s)) }\end{array}$ & 12.765 & $8.506-19.16$ & $<0.001$ & 15.283 & $\begin{array}{l}9.101- \\
25.663\end{array}$ & $<0.001$ \\
\hline $\begin{array}{l}{ }^{*} \text { Excessive loops of the leads in the } \\
\text { heart (any)/ECHO }\end{array}$ & 2.790 & $1.878-4.143$ & $<0.001$ & & & \\
\hline Excessive loop in the RA/ECHO & 2.031 & $1.290-3.197$ & 0.002 & & & \\
\hline Excessive loop in the TV/ECHO & 7.630 & $\begin{array}{l}4.701- \\
12.385\end{array}$ & $<0.001$ & & & \\
\hline Excessive loop in the RV/ECHO & 4.034 & $2.382-6.830$ & $<0.001$ & & & \\
\hline $\begin{array}{l}\text { Strong connective tissue scar } \\
\text { connection of the lead with heart } \\
\text { structures (any) }\end{array}$ & 2.489 & $1.605-3.861$ & $<0.001$ & & & \\
\hline $\begin{array}{l}\text { Strong connective tissue scar } \\
\text { connection of the lead with } \\
\text { tricuspid apparatus }\end{array}$ & 3.397 & $1.938-5.954$ & $<0.001$ & 2.004 & $0.958-4.196$ & 0.065 \\
\hline $\begin{array}{c}\text { Strong connective tissue scar } \\
\text { connection of the lead with RA wall }\end{array}$ & 2.934 & $1.520-5.663$ & $<0.001$ & 3.601 & $1.639-7.912$ & $<0.001$ \\
\hline $\begin{array}{l}\text { Strong connective tissue scar } \\
\text { connection of the lead with RV wall }\end{array}$ & 2.313 & $1.289-4.151$ & 0.005 & 2.151 & $0.992-4.663$ & 0.052 \\
\hline
\end{tabular}

* Due to the result of the two-factor regression analysis for the multivariate model, the variable "Lead (s) collision with TV (including excessive loop (s) of lead (s))" was selected, ignoring the change "excessive loops of the leads in the heart (any)/ECHO". OR for "leads collision" $=14.942 ; p<0.001$ and OR for "excessive loops" $=0.750$ $p=0.311$. Abbreviations: AF—atrial fibrillation, CRT—cardiac resynchronization therapy, LDTVD—lead dependent tricuspid valve dysfunction, HV—high voltage lead, PASP—pulmonary artery systolic pressure, RA—right atrium, RV-right ventricle, TLE—-transvenous lead extraction, TV—-tricuspid valve.

Analysis of the survival showed better prognosis of patients with LDTVD with improvement of tricuspid valve function after TLE compared to the other LDTVD patients in short, mid and long-term follow up (Figure 2). 


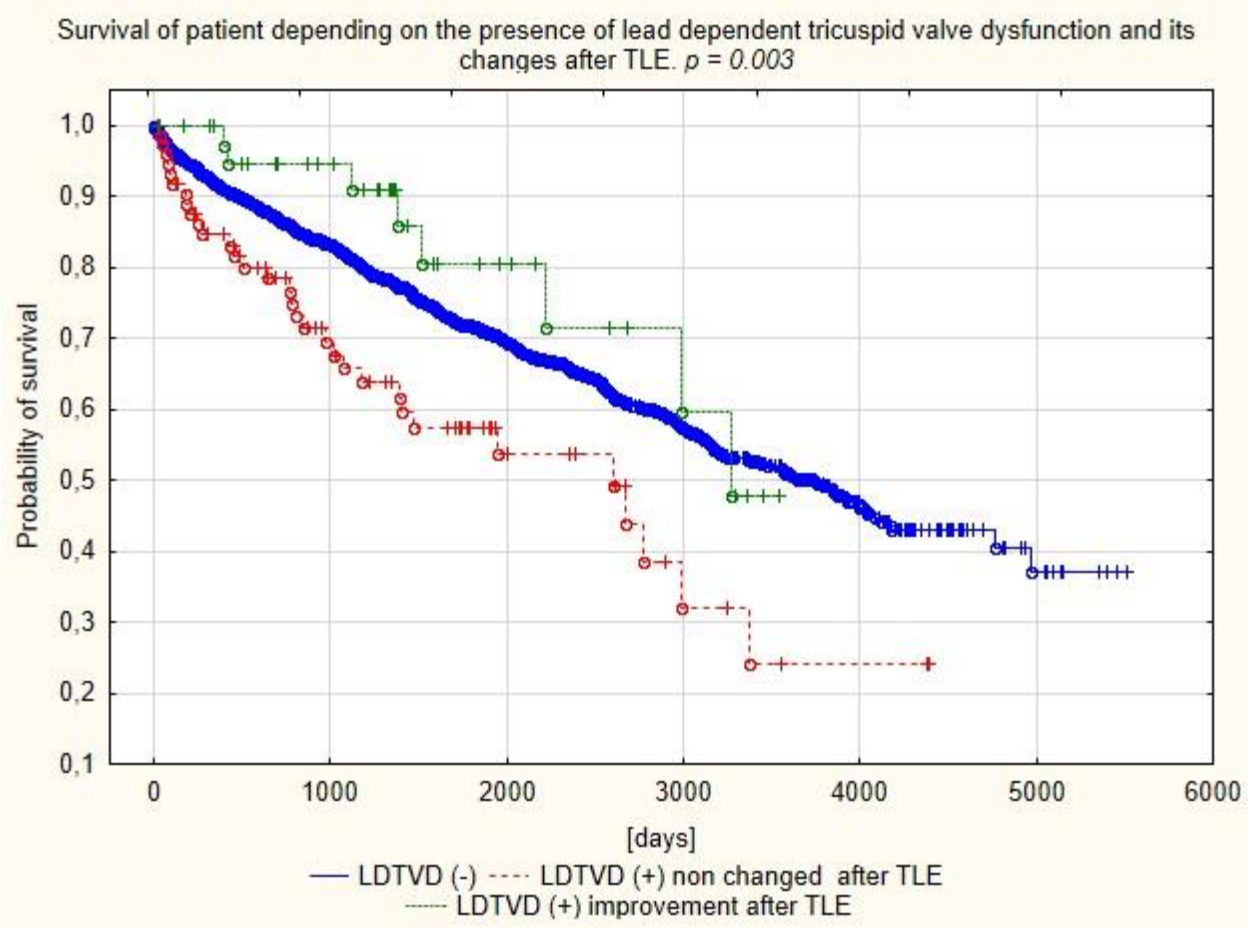

Figure 2. Kaplan-Meier curves of survival depending on the prevalence of LDTVD and changes after TLE

\section{Discussion}

The prevalence of lead-dependent tricuspid valve dysfunction is assessed in wide ranges depending on the studied population and the follow-up period after CIED implantation. According to previous studies comparing valve function before and after implantation, deterioration of tricuspid regurgitation is found in $7-45 \%$ of patients in Period 1 month to 6.5 years $[2-11,15]$. In the present study, the incidence of LDTVD was relatively low$4.44 \%$, however, in the current analysis TV function before and after CIED implantation was not compared, only influence of the lead on TV at various times after implantation (average time was about 8 years) as well as possible reduction of TR and survival after lead extraction procedure.

The diagnosis of LDTVD is difficult and requires careful echocardiographic evaluation. It has been shown to be the most common mechanism in the present study were propping upward or clamping (drawing) down the leaflet by the lead (85.7\%) (Figure 3). A similar mechanism is presented as leading in the current reports [15,17].

The most frequently reported risk factors for LDTVD are: female sex, the presence of atrial fibrillation, history of open-heart surgery, pre-existing TR, right ventricular dilatation, mitral regurgitation, enlargement of the left atrium, the presence of a high voltage (HV) lead, a greater number of leads passing through the tricuspid orifice, the specific position of the lead in relation to the valve annulus, leaflets, chordae tendinae, the place of pacing in the right ventricle, echocardiographic evidence of leaflet interference and elevated preimplant tricuspid regurgitation pressure gradient $[6,7,15-17,22,23]$. Analysis of the risk factors of LDTVD in the present study also showed a link between the female gender and some clinical factors: valvular heart disease permanent AF and heart failure. These factors do not initially cause LDTVD but are likely to increase the severity of LDTVD and worsen the NYHA class. The present study also showed a significant role for echocardiographic findings. In addition to factors considered in previous reports, such as dilation of the right ventricle and elevated PASP, a higher probability of LDTVD has also been shown in the case of collision of the lead with TV (especially excessive loop) and connective tissue adhesions of the leads with the cardiac structures: TV, RA or RV. The influence of an excessively long 
loop of the lead irritating the tricuspid valve on the development of LDTVD was already presented in an earlier study of the authors [24]. The loop located in the tricuspid ostium, by persistent valve opening, contributes to the development of a significant TR, at the same time it grows into the tricuspid apparatus, often causing TV stenosis.



Figure 3. Tricuspid valve dysfunction with significant regurgitation as a result of an unfavorable interaction of the lead with the valve leaflet. Monitoring of the TLE procedure by TEE examination. (A): Septal leaflet is clamping down (blue arrow) by a ventricular lead (red arrow) with impaired coaptation of the tricuspid valve TEE 3D. (B): Severe tricuspid regurgitation as a consequence of pulling the leaflet. TEE 2D color Doppler valve. (C): Imaging after TLE. Improving the mobility of the septal leaflet and the coaptation zone (blue arrow). TEE 3D. (D): Significant improvement in the degree of valve regurgitation after extraction of the lead. TEE 2D.

Several earlier reports have shown an influence of the time after CIED implantation on the development of LDTVD [7,15-17,25]. In the present study, the effect of duration of the lead in the heart has not been proven, but it should be taken into account that mean lead dwell time in whole study population was very long (95.36 \pm 67.10 months), and in the group of patients with LDTVD, it was significantly longer $(107.73 \pm 68.90 ; p=0.058)$. Undoubtedly, an expression of the influence of time on the development of LDTVD in the present study is the demonstration of the predictive role of the growth of leads to the structures of the heart.

Some studies document a close relationship between LDTVD and lead location that causes anterior or posterior leaflets impingement [26,27]. The course of the lead through the TV is also closely related to the target site of right ventricular pacing. In the formerly common apical pacing, the axial course through the TV is more favorable for a better cooptation of the leaflets. In turn, the currently more popular septal pacing may predispose to the occurrence of LDTVD through a much less axial course and a potential conflict with the chordae tendinae. In the present study, the tendency to more often LDTVD in patients with non-apical location of the lead tip was observed $(p=0.09)$, meanwhile, previous studies show completely different results Some reports have documented the unfavorable effect of septal pacing on the development of LDTVD $[8,28]$ while others 
suggest the opposite-adverse effect of apical pacing, probably related to contraction dyssynchrony $[9,29]$.

The present study also looked at the possibility of improving tricuspid valve function in patients with LDTVD after TLE. The reduction of TR after TLE was demonstrated in $35.29 \%$ of patients and was found more frequently in elderly patients with ischemic heart disease, qualified for TLE for prophylactic indications, and in patients with a smaller right ventricular size. Reports on the improvement of valve function in patients with LDTVD after TLE are sparse, in fact only the authors' previous analysis shows a significant reduction in TR [24], Other studies do not confirm the improvement of TV function in these patients, attributing it to the dilation of the tricuspid valve annulus persisted following lead removal $[30,31]$.

The relationship between LDTVD and worse survival is well known, and worsening of TR has been identified as an independent risk factor for mortality [15,16,32,33]. Analysis of long-term survival in the present study showed higher mortality in patients with LDTVD, but for the first time it was documented that this only applied to patients who did not improve after TLE. Patients with LDTVD who showed a decrease in TR after TLE had the best survival after approximately 5 years of follow-up.

\section{Conclusions}

Lead dependent tricuspid dysfunction is diagnosed in $4.44 \%$ of patients referred for lead extraction due to different reasons and only in 37.82\% LDTVD is main TLE indications. The most common mechanism of LDTVD is propping upward or clumping down the leaflet by the lead. Improvement of tricuspid valve function after TLE in population with very long lead dwell time (above 8 years) is observed in $35.29 \%$ of patients. The risk factors for LDTVD are primarily related to the course of the lead and its adhesion to the heart structures especially in the women. The influence of other clinical factors (valvular left heart disease, atrial fibrillation, heart failure resulting in higher pulmonary artery systolic pressure) results in dilation of the right ventricle and secondary favoring the dilatation of the valve annulus exacerbating its regurgitation. Patients with LDTVD have a worse long-term survival, but the improvement in valve function following TLE contributes to a significant reduction in mortality.

Supplementary Materials: The following supporting information can be downloaded at: https: / / www.mdpi.com/article/10.3390/jcm11010089/s1, Table S1: Clinical data. Classification according to the influence of TLE on LDTVD; Table S2: Indication, system and history of pacing-related factors. Classification according to the influence of TLE on LDTVD; Table S3: TLE procedure complexity, efficacy, complications, outcomes and long-term mortality after TLE. Classification according to the influence of TLE on LDTVD; Table S4: Echocardiographic findings/abnormalities. Classification according to the influence of TLE on LDTVD.

Author Contributions: A.P.—writing—original draft preparation; W.J.—methodology, statistical study, results interpretation; D.N.-investigation, data curation; A.T.-investigation; W.B.-investigation, D.S.-S.-investigation, data curation; K.D.-investigation, data curation; A.K.- supervision, writingreview and editing. All authors have read and agreed to the published version of the manuscript.

Funding: This research received no external funding.

Institutional Review Board Statement: The study was conducted according to the guidelines of the Declaration of Helsinki, and approved by the Bioethics Committee at the Regional Chamber of Physicians in Lublin no. 288/2018/KB/VII.

Informed Consent Statement: Written informed consent has been obtained from the patient(s) to publish this paper.

Data Availability Statement: Readers can access the data supporting the conclusions of the study at www.usuwanieelektrod.pl (accessed on 2 November 2021).

Conflicts of Interest: The authors declare no conflict of interest. 


\section{References}

1. Nachnani, G.H.; Gooch, A.S.; Hsu, I. Systolic Murmurs Induced by Pacemaker Catheters. Arch. Intern. Med. 1969, 124, $202-205$. [CrossRef]

2. Gould, L.; Reddy, C.V.; Yacob, U.; Teich, M.; DeMartino, A.; DePalma, D.; Gomprecht, R.F. Perforation of the tricuspid valve by a transvenous pacemaker. JAMA 1974, 230, 86-87. [CrossRef] [PubMed]

3. Paniagua, D.; Aldrich, H.R.; Lieberman, E.H.; Lamas, G.A.; Agatston, A.S. Increased prevalence of significant tricuspid regurgitation in patients with transvenous pacemakers leads. Am. J. Cardiol. 1998, 82, 1130-1132. [CrossRef]

4. De Cock, C.C.; Vinkers, M.; Van Campe, L.C.; Verhorst, P.M.; Visser, C.A. Long-term outcome of patients with multiple ( $\geq 3$ ) noninfected transvenous leads: A clinical and echocardiographic study. Pacing Clin. Electrophysiol. 2000, 23, 423-426. [CrossRef]

5. Klutstein, M.; Balkin, J.; Butnaru, A.; Ilan, M.; Lahad, A.; Rosenmann, D. Tricuspid incompetence following permanent pacemaker implantation. Pacing Clin. Electrophysiol. 2009, 32 (Suppl. S1), S135-S137. [CrossRef] [PubMed]

6. Kim, J.B.; Spevack, D.M.; Tunick, P.A.; Bullinga, J.R.; Kronzon, I.; Chinitz, L.A.; Reynolds, H.R. The effect of transvenous pacemaker and implantable cardioverter defibrillator lead placement on tricuspid valve function: An observational study. J. Am. Soc. Echocardiogr. 2008, 21, 284-287. [CrossRef]

7. Al-Bawardy, R.; Krishnaswamy, A.; Rajeswaran, J.; Bhargava, M.; Wazni, O.; Wilkoff, B.; Tuzcu, E.M.; Martin, D.; Thomas, J.; Blackstone, E.; et al. Tricuspid regurgitation and implantable devices. Pacing Clin. Electrophysiol. 2015, 38, 259-266. [CrossRef] [PubMed]

8. Lee, R.C.; Friedman, S.E.; Kono, A.T.; Greenberg, M.L.; Palac, R.T. Tricuspid Regurgitation Following Implantation of Endocardial Leads: Incidence and Predictors. Pacing Clin. Electrophysiol. 2015, 38, 1267-1274. [CrossRef]

9. Saito, M.; Iannaccone, A.; Kaye, G.; Negishi, K.; Kosmala, W.; Marwick, T.H.; PROTECT-PACE Investigator. Effect of Right Ventricular Pacing on Right Ventricular Mechanics and Tricuspid Regurgitation in Patients With High-Grade Atrioventricular Block and Sinus Rhythm (from the Protection of Left Ventricular Function During Right Ventricular Pacing Study). Am. J. Cardiol. 2015, 116, 1875-1882. [CrossRef] [PubMed]

10. Fanari, Z.; Hammami, S.; Hammami, M.B.; Shuraih, M. The effects of right ventricular apical pacing with transvenous pacemaker and implantable cardioverter defibrillator on mitral and tricuspid regurgitation. J. Electrocardiol. 2015, 48, 791-797. [CrossRef]

11. Arabi, P.; Özer, N.; Ateş, A.H.; Yorgun, H.; Oto, A.; Aytemir, K. Effects of pacemaker and implantable cardioverter defibrillator electrodes on tricuspid regurgitation and right sided heart functions. Cardiol. J. 2015, 22, 637-644. [CrossRef]

12. Leibowitz, D.W.; Rosenheck, S.; Pollak, A.; Geist, M.; Gilon, D. Transvenous pacemaker leads do not worsen tricuspid regurgitation: A prospective echocardiographic study. Cardiology 2000, 93, 74-77. [CrossRef] [PubMed]

13. Kucukarslan, N.; Kirilmaz, A.; Ulusoy, E.; Yokusoglu, M.; Gramatnikovski, N.; Ozal, E.; Tatar, H. Tricuspid insufficiency does not increase early after permanent implantation of pacemaker leads. J. Card. Surg. 2006, 21, 391-394. [CrossRef]

14. Webster, G.; Margossian, R.; Alexander, M.E.; Cecchin, F.; Triedman, J.K.; Walsh, E.P.; Berul, C.I. Impact of transvenous ventricular pacing leads on tricuspid regurgitation in pediatric and congenital heart disease patients. J. Interv. Card. Electrophysiol. 2008, 21, 65-68. [CrossRef] [PubMed]

15. Seo, J.; Kim, D.Y.; Cho, I.; Hong, G.R.; Ha, J.W.; Shim, C.Y. Prevalence, predictors, and prognosis of tricuspid regurgitation following permanent pacemaker implantation. PLoS ONE 2020, 15, e0235230. [CrossRef]

16. Riesenhuber, M.; Spannbauer, A.; Gwechenberger, M.; Pezawas, T.; Schukro, C.; Stix, G.; Schneider, M.; Goliasch, G.; Anvari, A.; Wrba, T.; et al. Pacemaker lead-associated tricuspid regurgitation in patients with or without pre-existing right ventricular dilatation. Clin. Res. Cardiol. 2021, 110, 884-894. [CrossRef] [PubMed]

17. Lee, W.C.; Fang, H.Y.; Chen, H.C.; Chen, Y.L.; Tsai, T.H.; Pan, K.L.; Lin, Y.S.; Liu, W.H.; Chen, M.C. Progressive tricuspid regurgitation and elevated pressure gradient after transvenous permanent pacemaker implantation. Clin. Cardiol. 2021, 44, 1098-1105. [CrossRef] [PubMed]

18. Lancellotti, P.; Moura, L.; Pierard, L.A.; Agricola, E.; Popescu, B.A.; Tribouilloy, C.; Hagendorff, A.; Monin, J.L.; Badano, L.; Zamorano, J.L. European Association of Echocardiography recommendations for the assessment of valvular regurgitation. Part 2: Mitral and tricuspid regurgitation (native valve disease). Eur. J. Echocardiogr. 2010, 11, 307-332. [CrossRef]

19. Zoghbi, W.A.; Adams, D.; Bonow, R.O.; Enriquez-Sarano, M.; Foster, E.; Grayburn, P.A.; Hahn, R.T.; Han, Y.; Hung, J.; Lang, R.M.; et al. Recommendations for Noninvasive Evaluation of Native Valvular Regurgitation: A Report from the American Society of Echocardiography Developed in Collaboration with the Society for Cardiovascular Magnetic Resonance. J. Am. Soc. Echocardiogr. 2017, 30, 303-371. [CrossRef]

20. Kusumoto, F.M.; Schoenfeld, M.H.; Wilkoff, B.; Berul, C.I.; Birgersdotter-Green, U.M.; Carrillo, R.; Cha, Y.M.; Clancy, J.; Deharo, J.C.; Ellenbogen, K.A.; et al. 2017 HRS expert consensus statement on cardiovascular implantable electronic device lead management and extraction. Heart Rhythm. 2017, 14, e503-e551. [CrossRef]

21. Bongiorni, M.G.; Burri, H.; Deharo, J.C.; Starck, C.; Kennergren, C.; Saghy, L.; Rao, A.; Tascini, C.; Lever, N.; Kutarski, A.; et al. 2018 EHRA expert consensus statement on lead extraction: Recommendations on definitions, endpoints, research trial design, and data collection requirements for clinical scientific studies and registries: Endorsed by APHRS/HRS/LAHRS. Europace 2018, 20, 1217. [CrossRef] [PubMed]

22. Al-Mohaissen, M.A.; Chan, K.L. Tricuspid Regurgitation Following Implantation of a Pacemaker/Cardioverter-Defibrillator. Curr. Cardiol. Rep. 2013, 15, 357. [CrossRef] [PubMed] 
23. Anvardeen, K.; Rao, R.; Hazra, S.; Hay, K.; Dai, H.; Stoyanov, N.; Birnie, D.; Dwivedi, G.; Chan, K.L. Lead-Specific Features Predisposing to the Development of Tricuspid Regurgitation After Endocardial Lead Implantation. CJC Open 2019, 31, 316-323. [CrossRef]

24. Polewczyk, A.; Kutarski, A.; Tomaszewski, A.; Brzozowski, W.; Czajkowski, M.; Polewczyk, M.; Janion, M. Lead dependent tricuspid dysfunction: Analysis of the mechanism and management in patients referred for transvenous lead extraction. Cardiol. J. 2013, 20, 402-410. [CrossRef]

25. Najib, M.Q.; Vittala, S.S.; Challa, S.; Raizada, A.; Tondato, F.J.; Lee, H.R.; Chaliki, H.P. Predictors of severe tricuspid regurgitation in patients with permanent pacemaker or automatic implantable cardioverter-defibrillator leads. Tex. Heart Inst. J. 2013, 40, 529-533.

26. Mediratta, A.; Addetia, K.; Yamat, M.; Moss, J.D.; Nayak, H.M.; Burke, M.C.; Weinert, L.; Maffessanti, F.; Jeevanandam, V.; Mor-Avi, V.; et al. 3D echocardiographic location of implantable device leads and mechanism of associated tricuspid regurgitation. JACC Cardiovasc. Imaging 2014, 7, 337-347. [CrossRef]

27. Addetia, K.; Maffessanti, F.; Mediratta, A.; Yamat, M.; Weinert, L.; Moss, J.D.; Nayak, H.M.; Burke, M.C.; Patel, A.R.; Kruse, E.; et al. Impact of implantable transvenous device lead location on severity of tricuspid regurgitation. J. Am. Soc. Echocardiogr. 2014, 27, 1164-1175. [CrossRef] [PubMed]

28. Zhang, H.X.; Qian, J.; Hou, F.Q.; Liu, Y.N.; Mao, J.H. Comparison of right ventricular apex and right ventricular outflow tract septum pacing in the elderly with normal left ventricular ejection fraction: Long-term follow-up. Kardiol. Pol. 2012, 70, 1130-1139.

29. Schleifer, J.W.; Pislaru, S.V.; Lin, G.; Powell, B.D.; Espinosa, R.; Koestler, C.; Thome, T.; Polk, L.; Li, Z.; Asirvatham, S.J.; et al. Effect of ventricular pacing lead position on tricuspid regurgitation: A randomized prospective trial. Heart Rhythm. 2018, 15, 1009-1016. [CrossRef]

30. Nazmul, M.N.; Cha, Y.M.; Lin, G.; Asirvatham, S.J.; Powell, B.D. Percutaneous pacemaker or implantable cardioverter-defibrillator lead removal in an attempt to improve symptomatic tricuspid regurgitation. Europace 2013, 15, 409-413. [CrossRef]

31. Migliore, F.; Zorzi, A.; Bertaglia, E.; Leoni, L.; Siciliano, M.; De Lazzari, M.; Ignatiuk, B.; Veronese, M.; Verlato, R.; Tarantini, G.; et al. Incidence, management, and prevention of right ventricular perforation by pacemaker and implantable cardioverter defibrillator leads. Pacing Clin. Electrophysiol. 2014, 37, 1602-1609. [CrossRef] [PubMed]

32. Höke, U.; Auger, D.; Thijssen, J.; Wolterbeek, R.; van der Velde, E.T.; Holman, E.R.; Schalij, M.J.; Bax, J.J.; Delgado, V.; Marsan, N.A. Significant lead-induced tricuspid regurgitation is associated with poor prognosis at long-term follow-up. Heart 2014, 100, 960-968. [CrossRef] [PubMed]

33. Delling, F.N.; Hassan, Z.K.; Piatkowski, G.; Tsao, C.W.; Rajabali, A.; Markson, L.J.; Zimetbaum, P.J.; Manning, W.J.; Chang, J.D.; Mukamal, K.J. Tricuspid regurgitation and mortality in patients with transvenous permanent pacemaker leads. Am. J. Cardiol. 2016, 117, 988-992. [CrossRef] [PubMed] 